
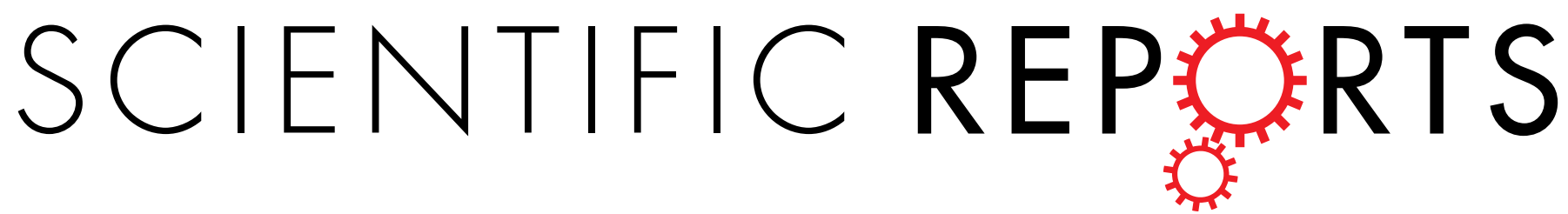

\title{
OPEN
}

Received: 13 March 2018

Accepted: 30 July 2018

Published online: 30 August 2018

\section{Reproductive factors and molecular subtypes of breast cancer among premenopausal women in Latin America: the PRECAMA study}

Isabelle Romieu ${ }^{1}$, Carine Biessy ${ }^{1}$, Marion Carayol ${ }^{2}$, Mathilde His ${ }^{1}$, Gabriela Torres-Mejía ${ }^{3}$, Angélica Ángeles-Llerenas ${ }^{3}$, Gloria Inés Sánchez ${ }^{4}$, Roberto Jaramillo ${ }^{5}$, Edgar Navarro ${ }^{6}$, Carolina Porras ${ }^{7}$, Rebecca Ocampo ${ }^{7}$, Ana Cecilia Rodriguez ${ }^{7}$, Maria Luisa Garmendia ${ }^{8}$, Eva Bustamante ${ }^{9}$, Magali Olivier ${ }^{10}$, Peggy Porter ${ }^{11}$, Sabina Rinaldi ${ }^{1}$ \& On behalf of the PRECAMA team*

Etiological differences among breast cancer (BC) subtypes have not been clearly established, especially among young women in Latin America. This study examined the relationship between reproductive factors and $B C$ subtypes among $288 \mathrm{BC}$ cases (20-45 years) and population-based matched controls in four Latin American countries. Immunohistochemistry was determined centrally. Associations between BC and reproductive factors were determined. Older age at first full-term pregnancy (FFTP) (Odds Ratio $(\mathrm{OR})=1.11 ; 95 \%$ Confidence Interval $(\mathrm{Cl}), 1.04-1.19$ per year), longer time between menarche and FFTP $(\mathrm{OR}=1.12 ; 95 \% \mathrm{Cl}: 1.04-1.20$ per year $)$, and older age at last pregnancy $(\mathrm{OR}=1.10 ; 95 \% \mathrm{Cl}, 1.02-1.19$ per year) were associated with an increased risk of estrogen receptor positive $(E R+)$ tumors $(n=122)$. Ever pregnant $(\mathrm{OR}=0.35 ; 95 \% \mathrm{Cl}, 0.13-0.96)$, number of childbirths $(\mathrm{OR}=0.64 ; 95 \% \mathrm{Cl}, 0.47-0.87$ per child $)$, time since last birth $(\mathrm{OR}=0.92 ; 95 \% \mathrm{Cl}, 0.85-0.99$ per year), and history of breastfeeding $(\mathrm{OR}=0.23$; $95 \% \mathrm{Cl}, 0.09-0.58)$ were inversely associated with the risk of $\mathrm{ER}+$ tumor. Older age at menarche $(\mathrm{OR}=0.63 ; 95 \% \mathrm{Cl}, 0.45-0.89$ per year) and longer duration of breastfeeding $(\mathrm{OR}=0.97 ; 95 \% \mathrm{Cl}$, 0.94-1.01 per month) were inversely associated with estrogen receptor negative (ER-) tumors $(n=48)$. Reproductive factors may be differentially associated with $\mathrm{BC}$ subtypes in young Latin American women.

Breast cancer (BC) in young women is a leading cause of death and remains so despite more intensive treatment than in older women ${ }^{1}$. This may be related to different risk factors and tumor biology in young women. Receptor expression and tumor genomics may be associated with distinct reproductive, personal, and behavioral factors (e.g. obesity and diet). In Latin American (LA) women, $20 \%$ of BC occurs at ages 20-45 years, a higher proportion than in Westernized populations ${ }^{2}$, and this substantial number of incident BC cases among young LA women can only be partly explained by the population age structure ${ }^{3}$. This understudied population is currently undergoing significant reproductive and lifestyle transitions ${ }^{4}$ that offer unique contrasts in exposures to study factors associated with BC subtypes.

Reproductive factors are the group of factors with the strongest and most consistent associations with BC risk $^{5}$. Known risk factors associated with $\mathrm{BC}$ include age at menarche, age at first birth, and parity. Increasing parity is protective against breast cancer, but the effects of younger age at first birth and parity appear to be smaller in

\footnotetext{
${ }^{1}$ Section of Nutrition and Metabolism, International Agency for Research on Cancer, Lyon, France. ${ }^{2}$ Val D'Aurelle Montpellier Cancer Institute (ICM), Montpellier, France. ${ }^{3}$ Centre for Population Health Research, National Institute of Public Health, Cuernavaca, Mexico. ${ }^{4}$ Group Infection and Cancer, School of Medicine, University of Antioquia, Medellín, Colombia. ${ }^{5} \mathrm{Hemato}$ Oncologos, Cali, Colombia. ${ }^{6}$ Grupo Proyecto UNI-Barranquilla, Universidad del Norte, Barranquilla, Colombia. ${ }^{7}$ Agencia Costarricense de Investigaciones Biomédicas (ACIB)-Fundación INCIENSA, San José, Costa Rica. ${ }^{8}$ Instituto de Nutrición y de Tecnología de los Alimentos, Santiago, Chile. ${ }^{9}$ Instituto Oncológico Fundación Arturo López Pérez, Providencia, Santiago, Chile. ${ }^{10}$ Molecular Mechanisms and Biomarkers Group, International Agency for Research on Cancer, Lyon, France. ${ }^{11}$ Divisions of Human Biology and Public Health Sciences, Fred Hutchinson Cancer Research Center, Seattle, USA. *A comprehensive list of the team members appears at the end of the paper. Correspondence and requests for materials should be addressed to S.R. (email: rinaldis@iarc.fr)
} 
women diagnosed with $\mathrm{BC}$ at age $<40$ years, and there is a transient increase in the risk of $\mathrm{BC}$ after each birth $^{6,7}$. Few studies have focused on risk factors for BC in young women, and these studies have mainly been conducted in Caucasian women ${ }^{8}$, with only limited data in Latin American or U.S Hispanic women ${ }^{2,9}$. In addition, in-depth knowledge of molecular and pathological characteristics of BC in young women is lacking, in particular in Latin America, with major consequences for cancer treatment and survival. We therefore conducted a multicenter population-based case-control study on BC in women aged 20 to 45 years across four Latin American countries (Chile, Colombia, Costa Rica, and Mexico) to determine BC subtypes and associated risk factors. In this report, we focus on the role of reproductive factors.

\section{Methods}

PRECAMA study. The PRECAMA study is an ongoing population-based case-control study coordinated by the International Agency for Research on Cancer (IARC) and involves scientific teams in four LA countries (Chile, Colombia, Costa Rica, and Mexico). Through IARC and a central laboratory (the Porter Lab) at the Fred Hutchinson Cancer Research Center (FHCRC) in Seattle, the research teams have harmonized and standardized protocols in the participating centers for recruitment of cases and controls, collection and storage of blood samples, tumor block fixation and handling, and pathology review. A central web-based database has been developed. The pilot phase of the study started in 2012. All participants gave written informed consent before enrolment, and the study protocols were approved by the institutional review boards of Chile (Oncologic Institute Foundation Arturo Lopez Pérez and National Cancer Institute), Colombia (Cancer Institute Las Americas and University of Antioquia), Costa Rica (Costa Rican Institute of Clinical Research (ICIC) and Center for Strategic Development and Information in Health and Social Security (CENDEISSS) of the Costa Rican Social Security Fund (CCSS)), Mexico (National Institute of Public Health and the Social Security Mexican Institute), and the International Agency for Research on Cancer (IARC). All methods were performed in accordance with the relevant guidelines and regulations of these approvals.

Selection of cases. Incident cases of primary invasive BC were recruited from large general or cancer-specific hospitals or private oncology institutes providing services to large urban populations with a wide range of socioeconomic status. The inclusion criteria were: age 20 to 45 years, residence for at least 3 years in the same city district and having an incident primary invasive BC with positive biopsy and clinical staging according to tumor-node-metastasis (TNM) standards. Women with a recent biopsy diagnosis of BC (incident case) or a referral to the breast surgeon because of suspicious mammography that was confirmed as BC were approached by a nurse and/or a breast surgeon and invited to participate in the study before starting any treatment.

Selection of controls. Controls were randomly selected from the underlying population residing in the same city district (neighborhood) as the case for at least 3 years using a standardized multilevel sampling frame. In Chile, because of logistic constraints, some controls were referred by the cases (acquaintances but not relatives). Controls were matched to cases on age ( \pm 3 years), city district of residence, and health insurance institution.

Exposure assessment. During the recruitment visit of cases and controls, trained nurses administered the lifestyle and food frequency questionnaires, conducted anthropometric measurements (weight, height, waist circumference, hip circumference, and sitting height), and collected fasting biological samples (blood and spot urine samples).

The lifestyle questionnaire included information on socioeconomic status during infancy and early childhood (based on parental education and occupation, place of residence, and type of housing during childhood), health and reproductive history (age at menarche, pregnancy, number of births, age at each birth, breastfeeding, history of benign breast disease, use of hormones (e.g. oral contraceptives), smoking habits, alcohol intake, maximum attained weight, body silhouette at different ages, physical activity (household and recreational) and hours per day spent sedentary (e.g. watching television), and family history of cancer.

Pathology review and immunohistochemical analyses. Prepared histology sections from tumor biopsy, obtained before any treatment, or obtained during surgery if no adjuvant therapy was administered, were reviewed for diagnosis, tumor grade, lymphovascular invasion, and stromal and lymphocyte response in a centralized laboratory in Seattle, USA (the Porter Lab, FHCRC). Tumor samples with $\geq 1 \%$ immunostained tumor cell nuclei were considered positive (Estrogen receptor positive (ER+), Progesterone receptor positive $(\mathrm{PR}+)$ ). For human epidermal growth factor receptor 2 (HER2), samples were considered positive if there was strong membrane immunostaining $(3+)$ and negative otherwise. In addition, the expression percentages of p53 (classified as positive if $>10 \%$ ) and the proliferation marker Ki-67 (classified as high if $>14 \%$ ) were determined. Triple-negative (TN) tumors were defined as estrogen receptor negative (ER-), progesterone receptor negative $(\mathrm{PR}-$ ), and human epidermal growth factor receptor 2 negative (HER2-), and among the TN tumors basal-like cancers were defined as ER-, PR-, HER2-, and Epidermal growth factor receptor positive (EGFR+) and/or cytokeratin $5 / 6$ positive $(\mathrm{CK} 5 / 6+)$.

Statistical analyses. Descriptive statistics (median, 10th to 90th percentiles, and proportions) were calculated overall and stratified by tumor subtypes, considering ER+, ER-, and TN tumor classification. For categorical variables cut-off points were based on the distribution among controls. Conditional logistic regression was used to calculate odds ratio (OR) and 95\% confidence interval (CI) for the association of reproductive factors. In addition to age at menarche, ever pregnant (full term pregnancy), age at first and last full term pregnancy, time between menarche and first full term pregnancy, number of childbirths, history of breastfeeding and duration of breastfeeding, we created variables by combining number of childbirths and breastfeeding (categorical), number of childbirths and age at first full-term pregnancy (FFTP), using 21 years (the median age at FFTP) as the cut-off 
(categorical), and number of childbirths and time since last birth (categorical). Stratified analyses were conducted on ER+ and ER - tumors and TN tumors and compared with their corresponding matched controls. To determine the effect of each reproductive factor, our models were adjusted for age at first birth, number of childbirths, duration of breastfeeding, education level, physical activity, waist circumference, family history of breast cancer and history of benign breast disease. Our final multivariate models, adjusted for factors that changed the risk estimate by more than $10 \%$, included maternal education level (low, medium, or high), physical activity (moderate physical activity in hours per day), waist circumference (continuous), and history of benign breast disease (yes/ no). In reporting the results, a two-sided $P$ value less than 0.05 was considered statistically significant. Non-linear association between breastfeeding duration and BC was explored using splines with knots at 6 and 12 months ${ }^{10}$. Analyses were conducted using SAS (version 9.4, SAS Institute, Cary, NC) and STATA (version 14) software

\section{Results}

Characteristics of the study population. Among 288 matched cases and controls, the median age at recruitment was 40 years. Compared with controls, cases were more educated (34\% vs $16 \%$ with a high level) and had a higher prevalence of history of benign breast disease (35\% vs 13\%). Among reproductive variables, compared with controls, cases were less likely to ever being pregnant ( $83 \%$ vs $92 \%$ ), and, when they had a child, had fewer children ( $19 \%$ vs $32 \%$ had $\geq 3$ children), and were older at first ( $42 \%$ vs $24 \%$ for $\geq 25$ years) and last pregnancy ( $48 \%$ vs $38 \%$ for $>30$ years). Compared to controls, cases had longer time between menarche and FFTP (63\% vs $44 \%$ for time $>8$ years), shorter time since last birth ( $42 \%$ vs $54 \%$ for time $\geq 10$ years), and were less likely to have breastfed ( $89 \%$ vs $95 \%$ ), and when they breastfed, they did so for a shorter duration ( $40 \%$ vs $60 \%$ for duration $>12$ months). Body mass index was slightly higher in controls than in cases $\left(28.3 \mathrm{~kg} / \mathrm{m}^{2} \mathrm{vs} 26.1 \mathrm{~kg} / \mathrm{m}^{2}\right)$, as was median waist circumference $(93 \mathrm{~cm}$ vs $90 \mathrm{~cm}$ ). Moderate physical activity was higher in controls ( $2.7 \mathrm{vs} 1.5$ hours per day), while sedentary behavior was higher in cases than in controls (14.3 vs 12.9 hours per day) (Table 1 ).

Table 2 describes BC subtypes according to standardized immunohistochemistry (IHC) for the 169 cases for which IHC is currently available. Of these cases, $72 \%$ were ER+, $28 \%$ were ER-, $19 \%$ were HER $2+$, and $21 \%$ were TN (ER-/PR-/HER2-). Among the TN, 92\% (33/36) were classified as basal-like. The proportions of p53 positive $(>10 \%)$ and Ki-67 high $(>14 \%)^{11}$ were the largest in TN tumors.

Reproductive factors and overall breast cancer risk. In multivariate conditional logistic regression analyses (adjusting for education level, history of benign breast disease, waist circumference, and physical activity), older age at FFTP $(\mathrm{OR}=1.06$; $95 \% \mathrm{CI}, 1.01-1.11$ per year), longer time between menarche and FFTP $(\mathrm{OR}=1.67 ; 95 \% \mathrm{CI}, 1.06-2.64$ comparing $\leq 8$ years vs $>8$ years $)$, and older age at last pregnancy $(\mathrm{OR}=1.99$; $95 \%$ CI, 1.09-3.61 comparing $\leq 25$ years vs $>30$ years) were associated with an increased risk of BC. Older age at menarche $(\mathrm{OR}=0.89 ; 95 \% \mathrm{CI}, 0.80-0.99$ per year $)$, ever being pregnant $(\mathrm{OR}=0.53 ; 95 \% \mathrm{CI}, 0.29-0.97)$, a longer time since last birth ( $\mathrm{OR}=0.46$; $95 \% \mathrm{CI}, 0.28-0.77$ comparing $<10$ years vs $\geq 10$ years), higher number of childbirths $(\mathrm{OR}=0.82 ; 95 \% \mathrm{CI}, 0.67-1.00$ per child), history of breastfeeding ( $\mathrm{OR}=0.56$; 95\% CI, 0.34-0.93), and a longer duration of breastfeeding among parous women $(\mathrm{OR}=0.42 ; 95 \% \mathrm{CI}, 0.18-0.94$ comparing $\leq 12$ months vs $>12$ months) were associated with a decreased risk of BC (Table 3 ).

When analyses were stratified by history of breastfeeding (ever vs never), women who had $\geq 2$ children and who had ever breastfed had a $48 \%$ lower risk of BC than nulliparous women (OR $=0.52 ; 95 \% \mathrm{CI}, 0.27-0.98)$, while no association was observed among women who had one or more children and who had never breastfed $(\mathrm{OR}=1.14 ; 95 \% \mathrm{CI}, 0.44-2.94)$. Women who had $\geq 2$ children and had a last birth $\geq 10$ years before recruitment were at reduced risk of $\mathrm{BC}(\mathrm{OR}=0.44 ; 95 \% \mathrm{CI}, 0.22-0.90)$ compared with nulliparous women. When analyses where stratified by age at FFTP, women who had a FFTP at $<21$ years and had $\geq 2$ children had a $64 \%$ lower risk of $\mathrm{BC}$ than nulliparous women $(\mathrm{OR}=0.46 ; 95 \% \mathrm{CI}, 0.23-0.93)$, while women who had a FFTP at $\geq 21$ years and had $\geq 2$ children were also at decreased risk, but the decrease was not statistically significant (Table 4 ).

Reproductive factors and breast cancer subtypes. Specific reproductive variables were differently associated with ER + and ER - tumors (Table 5). In multivariate analyses, the risk of ER + tumors $(n=122)$ was positively related to older age at FFTP $(\mathrm{OR}=1.11$; 95\% CI, 1.04-1.19 per year), longer time between menarche and FFTP $(\mathrm{OR}=1.12 ; 95 \% \mathrm{CI}, 1.04-1.20$ per year), and older age at last pregnancy $(\mathrm{OR}=1.10 ; 95 \% \mathrm{CI}, 1.02-1.19$ per year), while it was inversely associated with ever pregnant $(\mathrm{OR}=0.35 ; 95 \% \mathrm{CI}, 0.13-0.96)$, parity $(\mathrm{OR}=0.64$; $95 \% \mathrm{CI}, 0.47-0.87$ per child), time since last birth $(\mathrm{OR}=0.92 ; 95 \% \mathrm{CI}, 0.85-0.99$ per year), and history of breastfeeding $(\mathrm{OR}=0.23 ; 95 \% \mathrm{CI}, 0.09-0.58)$ (Table 5$)$. Older age at menarche $(\mathrm{OR}=0.63 ; 95 \% \mathrm{CI}, 0.45-0.89$ per year $)$ and longer duration of breastfeeding $(\mathrm{OR}=0.97 ; 95 \% \mathrm{CI}, 0.94-1.01$ per month) were inversely associated with the risk of ER- cancers $(n=48)$. For TN tumors results were similar to those observed for ER- tumors (Table 5).

The association between duration of breastfeeding and BC subtypes was further explored using non-linear models. For ER + tumors, a significant protective effect of breastfeeding was observed within the first 6 months of breastfeeding $(\mathrm{OR}=0.74 ; 95 \% \mathrm{CI}, 0.60-0.91)$ while for ER- tumors a protective effect was significant for $\geq 12$ months of breastfeeding (OR $=0,87 ; 95 \% \mathrm{CI}, 0.76-0.99)$.

\section{Discussion}

This paper reports the first results on reproductive factors and risk of breast cancer in the PRECAMA study, a multicenter population-based case-control study conducted in young women in Latin American countries. Older age at first full-term pregnancy (FFTP) and longer time between menarche and FFTP were positively associated with risk of $\mathrm{BC}$ overall, while older age at menarche, number of childbirths, history of breastfeeding, and duration of breastfeeding were inversely associated with risk. In combined analyses, compared to nulliparous women, the lowest risk was observed among women with 2 or more childbirths and a history of breastfeeding. 


\begin{tabular}{|c|c|c|}
\hline Characteristic $^{\mathrm{a}, \mathrm{b}}$ & Controls $(n=288)$ & Cases $(n=288)$ \\
\hline Age at recruitment (years) & $40(31-44)$ & $40(30-44)$ \\
\hline \multicolumn{3}{|l|}{ Education level } \\
\hline$\leq$ Primary school & $82(28 \%)$ & $50(17 \%)$ \\
\hline Secondary school & $160(56 \%)$ & $142(49 \%)$ \\
\hline$>$ Secondary school & $46(16 \%)$ & $96(34 \%)$ \\
\hline Family history of breast cancer & $15(5 \%)$ & $17(6 \%)$ \\
\hline History of benign breast disease & $37(13 \%)$ & $101(35 \%)$ \\
\hline Age at menarche (years) & $12(11-15)$ & $12(10-15)$ \\
\hline$\leq 12$ & $156(54.2 \%)$ & $154(53.5 \%)$ \\
\hline$>12$ & $132(45.8 \%)$ & $134(46.5 \%)$ \\
\hline Pregnancy ever & $266(92 \%)$ & $240(83 \%)$ \\
\hline Age at FFTP $(\text { years })^{c}$ & $20(16-29)$ & $23(17-32)$ \\
\hline$<20$ & $107(40 \%)$ & $66(28 \%)$ \\
\hline $20-24$ & $95(36 \%)$ & $71(30 \%)$ \\
\hline$\geq 25$ & $64(24 \%)$ & $101(42 \%)$ \\
\hline Time between menarche and FFTP $\left(\right.$ years) $^{c}$ & $8(3-16)$ & $11(4-20)$ \\
\hline$\leq 8$ & $150(56 \%)$ & $87(37 \%)$ \\
\hline$>8$ & $116(44 \%)$ & $151(63 \%)$ \\
\hline Age at last pregnancy $\left(\right.$ years) ${ }^{c}$ & $28(22-35)$ & $30(23-38)$ \\
\hline$\leq 25$ & $93(35 \%)$ & $63(26 \%)$ \\
\hline $26-30$ & $73(27 \%)$ & $62(26 \%)$ \\
\hline$>30$ & $100(38 \%)$ & $113(48 \%)$ \\
\hline Time since last birth (years) $^{\mathrm{c}}$ & $10(3-18)$ & $8.5(2-18)$ \\
\hline$<10$ & $123(46 \%)$ & $138(58 \%)$ \\
\hline$\geq 10$ & $143(54 \%)$ & $100(42 \%)$ \\
\hline Parity $^{d}$ & $2(1-3)$ & $2(0-3)$ \\
\hline Nulliparous & $22(8 \%)$ & $48(17 \%)$ \\
\hline 1 child & $52(18 \%)$ & $84(30 \%)$ \\
\hline 2 children & $121(42 \%)$ & $96(34 \%)$ \\
\hline$\geq 3$ children & $92(32 \%)$ & $53(19 \%)$ \\
\hline Breastfeeding ever ${ }^{c}$ & $252(95 \%)$ & $213(89 \%)$ \\
\hline Duration of breastfeeding (months) ${ }^{c}$ & $20(4-48)$ & $12(2-42)$ \\
\hline Never & $14(5 \%)$ & $27(11 \%)$ \\
\hline$\leq 12$ & $92(35 \%) \rightarrow(37 \%)$ & $117(49 \%) \rightarrow(55 \%)$ \\
\hline$>12$ & $160(60 \%) \rightarrow(63 \%)$ & $96(40 \%) \rightarrow(45 \%)$ \\
\hline \multicolumn{3}{|l|}{ Anthropometric measurements } \\
\hline Weight (kg) & $68.5(53-92)$ & $64.5(51-81)$ \\
\hline Height $(\mathrm{m})$ & $1.56(1.50-1.65)$ & $1.57(1.49-1.66)$ \\
\hline Body mass index $\left(\mathrm{kg} / \mathrm{m}^{2}\right)$ & $28.3(21.8-36.4)$ & $26.1(20.7-32.9)$ \\
\hline Waist circumference $(\mathrm{cm})$ & $93(76-112)$ & $90(75-106)$ \\
\hline \multicolumn{3}{|l|}{ Physical activity (hours per day) } \\
\hline Moderate physical activity & $2.7(0.7-7.0)$ & $1.5(0.2-5.4)$ \\
\hline Light physical activity/Sedentary & $12.9(8.4-16.1)$ & $14.3(8-17)$ \\
\hline
\end{tabular}

Table 1. Characteristics of the study population for cases and controls. ${ }^{a}$ Median (10th percentile to 90 th percentile) or number (\%). ${ }^{\mathrm{b}}$ Missing cases/controls: 8 missing (7/1) for parity (number of children); 2 missing $(2 / 0)$ for age at FFTP, age at last pregnancy, time since last birth, and time between menarche and FFTP; 3 missing (1/2) for height, waist circumference, and body mass index. 'Parous women only; FFTP: first full-term pregnancy. ${ }^{\mathrm{d}}$ Parity: number of childbirths.

In our population, most tumors were $\mathrm{ER}+(72 \%)$, TN tumors represented $21 \%$, of which more than $90 \%$ were basal-like type (20\%). Ever being pregnant, younger age at FFTP, shorter time between menarche and FFTP, younger age at last pregnancy, longer time since last birth, parity, and history of breastfeeding were significantly associated with a decreased risk of ER + tumors, while older age at menarche and longer duration of breastfeeding were inversely associated with risk of ER - and TN tumor.

Few epidemiological studies have investigated the role of reproductive factors on the risk of BC in young, premenopausal women ${ }^{12}$. In particular, there is limited information on the specific reproductive factors associated with TN subtypes, as this phenotype is much less frequent than ER+ tumors ${ }^{7}$. Most of the studies published to date included only Caucasian women or Caucasian and African-American or Asian women ${ }^{12-16}$. 


\begin{tabular}{|l|l|l|l|l|}
\hline Hormone receptor status $^{\mathbf{a}}$ & $\begin{array}{l}\text { All cases } \\
\text { Col (\%) }\end{array}$ & $\begin{array}{l}\text { P53 positive }^{\mathbf{b}} \\
\text { Row (\%) }^{\mathbf{b}}\end{array}$ & $\begin{array}{l}\text { Ki-67 positive }^{\mathbf{c}} \\
\text { Row (\%) }^{\mathbf{2}}\end{array}$ & Age (years) $^{\mathbf{d}}$ \\
\hline ER+ & $122(72 \%)$ & $20(16 \%)$ & $88(72 \%)$ & $40.5(30-45)$ \\
\hline ER- & $48(28 \%)$ & $24(51 \%)$ & $45(96 \%)$ & $38.5(29-44)$ \\
\hline PR+ & $123(72 \%)$ & $21(17 \%)$ & $88(72 \%)$ & $41.0(30-45)$ \\
\hline PR- & $47(28 \%)$ & $24(51 \%)$ & $45(96 \%)$ & $38(29-44)$ \\
\hline HER2+ & $32(19 \%)$ & $16(50 \%)$ & $28(88 \%)$ & $39.5(28-44)$ \\
\hline HER2- & $138(81 \%)$ & $29(21 \%)$ & $105(76 \%)$ & $40(30-45)$ \\
\hline Triple-negative (ER-/PR-/HER2-) & $36(21 \%)$ & $19(53 \%)$ & $35(97 \%)$ & $38(30-45)$ \\
\hline Of which Basal-like (TN + EGFR+and/or CK5/6+) & $33(20 \%)$ & $17(51 \%)$ & $32(97 \%)$ & $36(30-45)$ \\
\hline
\end{tabular}

Table 2. Description of breast cancer cases $(n=170)$ according to hormone receptor status and other tumor characteristics. ${ }^{a}$ ER: estrogen receptor; PR: progesterone receptor; HER2: human epidermal growth factor receptor 2 . Overall score of $\geq 1 \%$ immunostained tumor cell nuclei was considered positive for $\mathrm{ER}+$ or $\mathrm{PR}+$; for HER2, was considered positive if membrane immunostaining $3+$ and negative otherwise. ${ }^{b}$ p53 positive when $>10 \%$; 1 participant with missing data. ${ }^{c} \mathrm{Ki}-67$ high when $>14 \% .{ }^{\mathrm{d}}$ Median (10th percentile to 90 th percentile); 1 participant with missing data.

A systematic review on the risk of intrinsic BC tumor subtypes, including 38 studies with pre- and postmenopausal BC cases and controls among Caucasian and Asian women, concluded that most established risk factors reflect risk factors for luminal A (ER+ and/or PR+, HER2-) BC and that some BC risk factors may be differentially associated with other intrinsic tumor subtype ${ }^{17}$. Among reproductive risk factors, number of childbirths and, to a lesser degree, history of breastfeeding had the strongest protective effect for luminal A BC, while younger age at menarche and older age at FFTP were associated with a greater risk. Older age at menarche and history of breastfeeding were protective factors for TN tumors. Our results are consistent with these findings, although, in this review, data were not stratified by age at diagnosis, so it is not possible to disentangle specific risk factors for BC in young women among the results observed.

More recently, a meta-analysis on reproductive behaviors and risk of developing BC, including 15 studies (10 case-control studies, 3 prospective cohorts, and 2 pooled analyses) among Caucasian, African-American, and Asian women, confirmed some of the previous observations ${ }^{12}$. In the studies providing data on BC among young women, higher number of childbirths and younger age at FFTP were associated with a decreased risk of luminal $\mathrm{BC}(\mathrm{ER}+$ or PR+ and HER2-), but not of TN tumors, while duration of breastfeeding was associated with a protective effect in both luminal and TN BC, as observed in the overall analyses ${ }^{13,14}$. Two recent studies focused on the same age range as our study ${ }^{15,18}$. In a study conducted in Seattle, including mostly white women, older age at menarche was protective against $\mathrm{TN} \mathrm{BC}{ }^{15}$. These results were not confirmed in a later study including a more mixed population with a small proportion of Hispanic (3.7\%) women ${ }^{18}$.

In the only cohort study that explored the association of reproductive risk factors and BC subtypes among women aged $<40$ years of primarily Caucasian descent, older age at menarche ( $>14$ years) was significantly associated with a decreased risk in ER+/PR + tumors, while in ER-/PR - tumors, results were not significant. The results also suggested a protective effect of increased number of childbirths in ER+/PR+ tumors and an increased risk with increasing number of childbirths in $\mathrm{ER}-/ \mathrm{PR}$ - tumors. Breastfeeding appeared to be slightly protective in both $\mathrm{ER}+/ \mathrm{PR}+$ and $\mathrm{ER}-/ \mathrm{PR}$ - tumors, but none of these results were statistically significant ${ }^{8}$.

In our study, reproductive risk factors for hormone-dependent tumors $(\mathrm{ER}+)$ are consistent with published data. Cross-classification of parity and breastfeeding supports a strong protective effect among women who had $\geq 2$ children and had breastfed compared with nulliparous women. Among ER- tumors and TN tumors, older age at menarche was a protective factor as observed in other studies ${ }^{15-17,19}$ and longer time between menarche and FFTP was marginally positively associated with ER- tumors. Ever pregnant or higher number of childbirths were not related to an increased risk of ER- or TN tumors, neither was age at FFTP. The biological explanation for the effect of pregnancy on BC risk is still unclear. Pregnancy has been shown to initiate cellular differentiation in mammary glands and lower susceptibility to carcinogenesis ${ }^{20}$. This could explain the finding that an older age at menarche and shorter period between menarche and FFTP has a protective effect on BC.

A longer duration of breastfeeding was protective against BC. Breastfeeding has been associated with a reduced risk of overall $\mathrm{BC}$, with a reduction in risk of $4.3 \%$ for each 12 months of breastfeeding ${ }^{21}$. A systematic review and meta-analysis concluded that breastfeeding in premenopausal women was related to a reduction in risk of $14 \%$, with a sharper decrease within the first 6 months of accumulated breastfeeding ${ }^{22}$. Considering BC subtypes, consistent results have been observed on the impact of breastfeeding on TN BC while some inconsistency has been observed for hormonal dependent BC. In a meta-analysis including 15 studies ( 3 prospective cohorts, 10 case-control studies and 2 pooled analyses), ever breastfeeding was associated with a reduced risk of developing both luminal A and TN subtypes ${ }^{12}$; while in a larger meta-analysis, including 27 distinct studies (8 prospective cohorts and 19 case- control studies) ever breastfeeding was inversely associated with ER- and PR$\mathrm{BC}$ as well as TN BC, but no significant association was observed with $\mathrm{ER}+\mathrm{PR}+\mathrm{BC}$ overall $^{23}$. In a recent pooled analysis of multiethnic studies in the US including a significant proportion of Hispanic women, longer duration of breastfeeding was associated with a borderline reduced risk of TN BC among women under 50 years of age ${ }^{19}$.

Our results are in line with those results and suggested a sharper decrease after 12 months of accumulated breastfeeding on the risk of ER- and TN BC, while the impact on ER + tumors would occur within the first 6 months. After pregnancy, an extended period of breastfeeding contributes to the functional ripening of the 


\begin{tabular}{|c|c|c|c|c|c|}
\hline \multirow[b]{2}{*}{ Factor } & \multirow{2}{*}{$\begin{array}{l}\mathrm{N} \\
\text { Cases/Controls } \\
\end{array}$} & \multirow{2}{*}{\begin{tabular}{|l|} 
Matched $^{\mathrm{a}}$ \\
OR $(95 \% \mathrm{CI})^{\mathrm{c}}$ \\
\end{tabular}} & \multirow[b]{2}{*}{ p-value ${ }^{a}$} & \multirow{2}{*}{\begin{tabular}{|l|} 
Multivariate $^{\mathrm{b}}$ \\
OR $(95 \% \mathrm{CI})^{\mathrm{c}}$
\end{tabular}} & \multirow[b]{2}{*}{ p-value ${ }^{b}$} \\
\hline & & & & & \\
\hline \multicolumn{6}{|l|}{ Education.level } \\
\hline$\leq$ Primary school & $50 / 82$ & 1.00 & & 1.00 & \\
\hline Secondary school & $142 / 160$ & $1.87(1.10-3.18)$ & 0.02 & $1.78(1.00-3.17)$ & 0.05 \\
\hline$>$ Secondary school & $96 / 46$ & $4.83(2.60-8.98)$ & $<0.0001$ & $4.25(2.19-8.27)$ & $<0.0001$ \\
\hline Family history of breast cancer & $17 / 15$ & $1.14(0.56-2.34)$ & 0.72 & $1.03(0.46-2.34)$ & 0.94 \\
\hline History of benign breast disease & $101 / 37$ & $3.46(2.24-5.36)$ & $<0.0001$ & $3.43(2.16-5.45)$ & $<0.0001$ \\
\hline \multicolumn{6}{|l|}{ Reproductive variables } \\
\hline Age at menarche (years) & $288 / 288$ & $0.93(0.85-1.01)$ & 0.10 & $0.89(0.80-0.99)$ & 0.04 \\
\hline$\leq 12$ & $154 / 156$ & 1.00 & & 1.00 & \\
\hline$>12$ & $134 / 132$ & $1.03(0.74-1.43)$ & 0.87 & $0.88(0.60-1.30)$ & 0.53 \\
\hline Pregnancy ever & $240 / 266$ & $0.41(0.24-0.71)$ & 0.001 & $0.53(0.29-0.97)$ & 0.04 \\
\hline Age at FFTP $(\text { years })^{d}$ & & $1.08(1.04-1.13)$ & $<0.0001$ & $1.06(1.01-1.11)$ & 0.01 \\
\hline$<20$ & 66/107 & 1.00 & & 1.00 & \\
\hline $20-24$ & $71 / 95$ & $1.03(0.62-1.69)$ & 0.92 & $0.74(0.41-1.33)$ & 0.32 \\
\hline$\geq 25$ & $101 / 64$ & $2.44(1.47-4.04)$ & 0.001 & $1.53(0.82-2.83)$ & 0.18 \\
\hline Time between menarche and FFTP (years) $^{d}$ & & $1.09(1.05-1.13)$ & $<0.0001$ & $1.07(1.03-1.12)$ & 0.001 \\
\hline$\leq 8$ & $87 / 150$ & 1.00 & & 1.00 & \\
\hline$>8$ & $151 / 116$ & $1.98(1.35-2.89)$ & $<0.0001$ & $1.67(1.06-2.64)$ & 0.03 \\
\hline Age at last pregnancy (years) ${ }^{\mathrm{d}}$ & & $1.06(1.02-1.10)$ & 0.004 & $1.07(1.03-1.13)$ & 0.003 \\
\hline$\leq 25$ & $63 / 93$ & 1.00 & & 1.00 & \\
\hline $26-30$ & $62 / 73$ & $1.25(1.76-2.06)$ & 0.38 & $1.31(0.72-2.39)$ & 0.37 \\
\hline$>30$ & $113 / 100$ & $1.78(1.07-2.95)$ & 0.03 & $1.99(1.09-3.61)$ & 0.02 \\
\hline Time since last birth (years) $^{\mathrm{d}}$ & & $0.95(0.91-0.99)$ & 0.009 & $0.94(0.90-0.99)$ & 0.01 \\
\hline$<10$ & $138 / 123$ & 1.00 & & 1.00 & \\
\hline$\geq 10$ & $100 / 143$ & $0.53(0.34-0.81)$ & 0.004 & $0.46(0.28-0.77)$ & 0.003 \\
\hline Parity ${ }^{\mathrm{d}}$ (per child) & & $0.66(0.55-0.78)$ & $<0.0001$ & $0.82(0.67-1.00)$ & 0.05 \\
\hline Nulliparous & $48 / 22$ & 1.00 & & 1.00 & \\
\hline 1 child & $84 / 52$ & $0.76(0.40-1.44)$ & 0.40 & $0.89(0.44-1.83)$ & 0.76 \\
\hline 2 children & $96 / 121$ & $0.36(0.20-0.65)$ & 0.001 & $0.53(0.27-1.03)$ & 0.06 \\
\hline$\geq 3$ children & $53 / 92$ & $0.25(0.13-0.48)$ & $<0.0001$ & $0.51(0.24-1.05)$ & 0.07 \\
\hline Breastfeeding ever & $213 / 252$ & $0.43(0.28-0.66)$ & $<0.0001$ & $0.56(0.34-0.93)$ & 0.03 \\
\hline Duration of breastfeeding (months) ${ }^{\mathrm{d}}$ & & $0.98(0.97-0.99)$ & 0.003 & $0.99(0.98-1.00)$ & 0.08 \\
\hline Never & $27 / 14$ & 1.00 & & 1.00 & \\
\hline$\leq 12$ & $117 / 92$ & $0.80(0.39-1.63)$ & 0.53 & $0.73(0.33-1.63)$ & 0.45 \\
\hline$>12$ & $96 / 160$ & $0.32(0.15-0.66)$ & 0.002 & $0.42(0.18-0.94)$ & 0.04 \\
\hline
\end{tabular}

Table 3. Odds ratios and $95 \%$ confidence intervals of association between breast cancer and reproductive

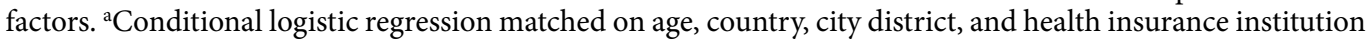
(when appropriate). ${ }^{\mathrm{b}}$ Conditional logistic regression matched on age, country, city district, and health insurance institution and adjusted for education level, history of benign breast disease, physical activity, and waist circumference when appropriate. ${ }^{\mathrm{c} O R s}$ are given for both continuous (unit of change) and categorical variables. dParous women only; FFTP: first full-term pregnancy.

glandular tissue, and its protective effect appears to be stronger in more aggressive tumors, basal-like $\mathrm{TN}^{24}$. Several mechanisms have been suggested, including differentiation of breast epithelium, a lower periodic influence of estrogen/progesterone on breast tissue, and excretion of cells with initial DNA damage from the breast ductal tissue $\mathrm{e}^{25}$.

Very few studies have focused on Latin American women. In a case-only study conducted among Mexican women, comparing TN with luminal A BC, women with an older age at FFTP were less likely to have TN BC, while women with $\geq 3$ full-term pregnancies were more likely to have TN BC. Breastfeeding for $\geq 12$ months was related to a doubling in the risk of $\mathrm{TN} \mathrm{BC}^{26}$. However, the high correlation between parity and breastfeeding makes it difficult to interpret the results. In addition, comparing risk factors across BC subtypes cannot provide evidence on risk factors for these specific subtypes, because of the lack of comparison with healthy controls.

The strengths of our study include: (1) the focus on young Latin American women, for whom little is known about the distribution of subtypes of BC and associated risk factors; (2) the use of a standardized methodology to collect data across centers; (3) the inclusion of incident BC cases (time between diagnosis and inclusion in the study was within 1 week) and selection of matched population-based controls; and (4) the centralization of tumor phenotyping through IHC in one laboratory, which ensures uniformity of BC phenotyping and therefore homogeneity in classification. Some limitations need to be mentioned. The sample size of the current analysis is 


\begin{tabular}{|l|l|l|l|l|l|}
\hline Reproductive variables & N & Matched $^{\mathbf{a}}$ & p-value $^{\mathbf{a}}$ & Multivariate $^{\mathbf{b}}$ & p-value $^{\mathbf{b}}$ \\
\hline Combination: Parity and breast feeding & $48 / 22$ & 1.00 & & 1.00 & \\
\hline Nulliparous & $27 / 14$ & $0.89(0.39-2.05)$ & 0.78 & $1.14(0.44-2.94)$ & 0.79 \\
\hline$\geq 1$ children, never breastfed & $66 / 45$ & $0.71(0.37-1.36)$ & 0.31 & $0.81(0.39-1.68)$ & 0.57 \\
\hline 1 child, ever breastfed & $147 / 207$ & $0.32(0.18-0.57)$ & $<\mathbf{0 . 0 0 0 1}$ & $0.52(0.27-0.98)$ & $\mathbf{0 . 0 4}$ \\
\hline$\geq 2$ children, ever breastfed & \multicolumn{5}{|l|}{} \\
\hline Combination: Parity and time since last birth \\
\hline Nulliparous & $48 / 22$ & 1.00 & 1.00 & \\
\hline 1 child, $<10$ years since last birth & $52 / 22$ & $1.28(0.59-2.79)$ & 0.53 & $1.79(0.74-4.35)$ & 0.20 \\
\hline 1 child, $\geq 10$ years since last birth & $30 / 30$ & $0.48(0.23-1.00)$ & $\mathbf{0 . 0 5}$ & $0.47(0.20-1.12)$ & 0.09 \\
\hline$\geq 2$ children, $<10$ years since last birth & $80 / 100$ & $0.38(0.20-0.71)$ & $\mathbf{0 . 0 0 3}$ & $0.66(0.32-1.35)$ & 0.25 \\
\hline$\geq 2$ children, $\geq 10$ years since last birth & $69 / 113$ & $0.28(0.15-0.52)$ & $<\mathbf{0 . 0 0 0 1}$ & $0.44(0.22-0.90)$ & $\mathbf{0 . 0 3}$ \\
\hline Combination: Parity and age at FFTP & \multicolumn{5}{|l|}{} \\
\hline Nulliparous & $48 / 22$ & 1.00 & 1.00 & \\
\hline 1 child, age at FFTP $<21$ years & $14 / 10$ & $0.81(0.32-2.07)$ & 0.66 & $1.06(0.36-3.14)$ & 0.92 \\
\hline 1 child, age at FFTP $\geq 21$ years & $68 / 42$ & $0.78(0.40-1.54)$ & 0.48 & $0.86(0.41-1.84)$ & 0.71 \\
\hline$\geq 2$ children, age at FFTP $<21$ years & $69 / 125$ & $0.26(0.14-0.48)$ & $<\mathbf{0 . 0 0 0 1}$ & $0.46(0.23-0.93)$ & $\mathbf{0 . 0 3}$ \\
\hline$\geq 2$ children, age at FFTP $\geq 21$ years & $80 / 88$ & $0.43(0.23-0.82)$ & $\mathbf{0 . 0 1}$ & $0.59(0.29-1.20)$ & 0.15 \\
\hline
\end{tabular}

Table 4. Odds ratios and $95 \%$ confidence intervals of breast cancer by combination of reproductive variables. ${ }^{a}$ Conditional logistic regression matched on age, country, city district, and health insurance institution (when appropriate). ${ }^{\mathrm{b} C o n d i t i o n a l ~ l o g i s t i c ~ r e g r e s s i o n ~ m a t c h e d ~ o n ~ a g e, ~ c o u n t r y, ~ c i t y ~ d i s t r i c t, ~ a n d ~ h e a l t h ~ i n s u r a n c e ~}$ institution and adjusted for education level, history of benign breast disease, physical activity, and waist circumference. ${ }^{c}$ FFTP: first full-term pregnancy, median age $=21$ years.

\begin{tabular}{|c|c|c|c|c|c|c|}
\hline \multirow[b]{2}{*}{ Reproductive variables } & \multicolumn{2}{|c|}{ ER+ vs Control $(n=122)$} & \multicolumn{2}{|c|}{ ER- vs Control $(n=48)$} & \multicolumn{2}{|c|}{ TN vs Control $(n=36$} \\
\hline & $\mathrm{OR}^{\mathrm{a}}(95 \% \mathrm{CI})$ & p-value ${ }^{b}$ & $\mathrm{OR}^{\mathrm{a}}(95 \% \mathrm{CI})$ & p-value ${ }^{b}$ & $\mathrm{OR}^{\mathrm{a}}(95 \% \mathrm{CI})$ & p-value ${ }^{b}$ \\
\hline Age at menarche (years) & $\begin{array}{l}1.02 \\
(0.87-1.19)\end{array}$ & 0.84 & $\begin{array}{l}0.63 \\
(0.45-0.89)\end{array}$ & 0.01 & $\begin{array}{l}0.67 \\
(0.46-0.98)\end{array}$ & 0.04 \\
\hline Pregnancy ever & $\begin{array}{l}0.35 \\
(0.13-0.96)\end{array}$ & 0.04 & $\begin{array}{l}1.12 \\
(0.22-5.72)\end{array}$ & 0.89 & $\begin{array}{l}0.53 \\
(0.07-3.91)\end{array}$ & 0.53 \\
\hline Age at FFTP (years) ${ }^{c}$ & $\begin{array}{l}1.11 \\
(1.04-1.19)\end{array}$ & 0.003 & $\begin{array}{l}1.03 \\
(0.91-1.17)\end{array}$ & 0.61 & $\begin{array}{l}0.97 \\
(0.84-1.13)\end{array}$ & 0.71 \\
\hline Time between menarche and FFTP (years) ${ }^{c}$ & $\begin{array}{l}1.12 \\
(1.04-1.20)\end{array}$ & 0.002 & $\begin{array}{l}1.10 \\
(0.97-1.26)\end{array}$ & 0.15 & $\begin{array}{l}1.06 \\
(0.91-1.23)\end{array}$ & 0.49 \\
\hline Age at last pregnancy (years) ${ }^{\mathrm{c}}$ & $\begin{array}{l}1.10 \\
(1.02-1.19)\end{array}$ & 0.01 & $\begin{array}{l}1.08 \\
(0.94-1.25)\end{array}$ & 0.29 & $\begin{array}{l}1.05 \\
(0.89-1.24)\end{array}$ & 0.55 \\
\hline Time since last birth (years) ${ }^{\mathfrak{c}}$ & $\begin{array}{l}0.92 \\
(0.85-0.99)\end{array}$ & 0.02 & $\begin{array}{l}0.95 \\
(0.83-1.09)\end{array}$ & 0.44 & $\begin{array}{l}0.99 \\
(0.84-1.16)\end{array}$ & 0.88 \\
\hline Parity $^{\mathrm{d}}$ & $\begin{array}{l}0.64 \\
(0.47-0.87)\end{array}$ & 0.005 & $\begin{array}{l}0.93 \\
(0.54-1.58)\end{array}$ & 0.78 & $\begin{array}{l}0.99 \\
(0.51-1.92)\end{array}$ & 0.98 \\
\hline Breastfeeding ever ${ }^{\mathrm{C}}$ & $\begin{array}{l}0.23 \\
(0.09-0.58)\end{array}$ & 0.002 & $\begin{array}{l}1.57 \\
(0.46-5.43)\end{array}$ & 0.47 & $\begin{array}{l}0.84 \\
(0.21-3.36)\end{array}$ & 0.80 \\
\hline Duration of breastfeeding (months) ${ }^{c}$ & \begin{tabular}{|l|}
0.99 \\
$(0.98-1.01)$
\end{tabular} & 0.48 & $\begin{array}{l}0.97 \\
(0.93-1.01)\end{array}$ & 0.13 & \begin{tabular}{|l}
0.97 \\
$(0.92-1.02)$
\end{tabular} & 0.20 \\
\hline
\end{tabular}

Table 5. Association of breast cancer and reproductive factors by hormone receptor status. ${ }^{\mathrm{a}} \mathrm{ORs}$ are given for continuous variables (unit of change). ${ }^{b}$ Conditional logistic regression matched on age, country, city district, and health insurance institution and adjusted for education level, benign breast diseases, physical activity, and waist circumference. ${ }^{c}$ Parous women only. FFTP: first full-term pregnancy. ${ }^{\mathrm{d}}$ Parity: number of childbirths.

limited, and subgroup analyses suffer from lack of statistical power in particular to explore cross-classification of reproductive variables.

This is the first multicenter breast cancer study in young Latin American women. Our results are in line with previous literature on risk factors for ER+ tumors in other populations. Estrogen receptor-negative and TN tumors were inversely associated with older age at menarche and longer duration of breastfeeding which provide support for breastfeeding promotion among young Latin American women. Given the modifiable nature of breastfeeding and its consistent protective effect on most aggressive tumors, targeted intervention to inform women on its beneficial impact and encourage the practice for period extended at least 1 year should be conducted. As continued accrual of cases and controls expands in our study, we will be able to classify further the subtypes of $\mathrm{BC}$ based on molecular markers and confirm these results. 


\section{Data Availability}

PRECAMA data and biospecimens are available for investigators who seek to answer important questions on health and disease in the context of research projects that are consistent with the legal and ethical standard practices of IARC/World Health Organization (WHO) and the PRECAMA Centres. The primary responsibility for accessing the data belongs to the PRECAMA centres that provided them. The use of a random sample of anonymised data from the PRECAMA study can be requested by contacting the corresponding author. The request will then be passed to members of the PRECAMA Steering Committee for deliberation.

\section{References}

1. Chollet-Hinton, L. et al. Breast cancer biologic and etiologic heterogeneity by young age and menopausal status in the Carolina Breast Cancer Study: a case-control study. Breast Cancer Res 18, 79, https://doi.org/10.1186/s13058-016-0736-y (2016).

2. Villarreal-Garza, C. et al. Breast cancer in young women in Latin America: an unmet, growing burden. Oncologist 18(Suppl), 26-34, https://doi.org/10.1634/theoncologist.18-S2-26 (2013).

3. Franco-Marina, F., Lopez-Carrillo, L., Keating, N. L., Arreola-Ornelas, H. \& Marie Knaul, F. Breast cancer age at diagnosis patterns in four Latin American Populations: A comparison with North American countries. Cancer Epidemiol 39, 831-837, https://doi. org/10.1016/j.canep.2015.10.004 (2015).

4. Popkin, B. M. Contemporary nutritional transition: determinants of diet and its impact on body composition. Proc Nutr Soc 70, 82-91, https://doi.org/10.1017/S0029665110003903 (2011).

5. Rosner, B., Colditz, G. A. \& Willett, W. C. Reproductive risk factors in a prospective study of breast cancer: the Nurses' Health Study. Am J Epidemiol 139, 819-835 (1994).

6. Pathak, D. R., Speizer, F. E., Willett, W. C., Rosner, B. \& Lipnick, R. J. Parity and breast cancer risk: possible effect on age at diagnosis. Int J Cancer 37, 21-25 (1986).

7. Narod, S. A. Breast cancer in young women. Nat Rev Clin Oncol 9, 460-470, https://doi.org/10.1038/nrclinonc.2012.102 (2012).

8. Warner, E. T. et al. Reproductive factors and risk of premenopausal breast cancer by age at diagnosis: are there differences before and after age 40? Breast Cancer Res Treat 142, 165-175, https://doi.org/10.1007/s10549-013-2721-9 (2013).

9. Hines, L. M. et al. Comparative analysis of breast cancer risk factors among Hispanic and non-Hispanic white women. Cancer 116, 3215-3223, https://doi.org/10.1002/cncr.25154 (2010).

10. Harrell, F. E. J. Regression Modeling Strategies: With Applications to Linear Models, Logistic Regression, and Survival Analysis. (Springer-Verlag New York, 200R1).

11. Scholzen, T. \& Gerdes, J. The Ki-67 protein: from the known and the unknown. J Cell Physiol 182, 311-322, https://doi.org/10.1002/ (SICI)1097-4652(200003)182:3<311::AID-JCP1>3.0.CO;2-9 (2000).

12. Lambertini, M. et al. Reproductive behaviors and risk of developing breast cancer according to tumor subtype: A systematic review and meta-analysis of epidemiological studies. Cancer Treat Rev 49, 65-76, https://doi.org/10.1016/j.ctrv.2016.07.006 (2016).

13. Ma, H. et al. Use of four biomarkers to evaluate the risk of breast cancer subtypes in the women's contraceptive and reproductive experiences study. Cancer Res 70, 575-587, https://doi.org/10.1158/0008-5472.CAN-09-3460 (2010).

14. Gaudet, M. M. et al. Risk factors by molecular subtypes of breast cancer across a population-based study of women 56 years or younger. Breast Cancer Res Treat 130, 587-597, https://doi.org/10.1007/s10549-011-1616-x (2011).

15. Dolle, J. M. et al. Risk factors for triple-negative breast cancer in women under the age of 45 years. Cancer Epidemiol Biomarkers Prev 18, 1157-1166, https://doi.org/10.1158/1055-9965.EPI-08-1005 (2009).

16. Li, H. et al. BMI, reproductive factors, and breast cancer molecular subtypes: A case-control study and meta-analysis. J Epidemiol 27, 143-151, https://doi.org/10.1016/j.je.2016.05.002 (2017).

17. Barnard, M. E., Boeke, C. E. \& Tamimi, R. M. Established breast cancer risk factors and risk of intrinsic tumor subtypes. Biochim Biophys Acta 1856, 73-85, https://doi.org/10.1016/j.bbcan.2015.06.002 (2015).

18. Li, C. I. et al. Reproductive factors and risk of estrogen receptor positive, triple-negative, and HER2-neu overexpressing breast cancer among women 20-44 years of age. Breast Cancer Res Treat 137, 579-587, https://doi.org/10.1007/s10549-012-2365-1 (2013).

19. John, E. M. et al. Reproductive history, breast-feeding and risk of triple negative breast cancer: The Breast Cancer Etiology in Minorities (BEM) study. Int J Cancer 142, 2273-2285, https://doi.org/10.1002/ijc.31258 (2018).

20. Althuis, M. D. et al. Etiology of hormone receptor-defined breast cancer: a systematic review of the literature. Cancer Epidemiol Biomarkers Prev 13, 1558-1568 (2004).

21. Collaborative Group on Hormonal Factors in Breast, C. Breast cancer and breastfeeding: collaborative reanalysis of individual data from 47. epidemiological studies in 30 countries, including 50302 women with breast cancer and 96973 women without the disease. Lancet 360, 187-195, https://doi.org/10.1016/S0140-6736(02)09454-0 (2002).

22. Unar-Munguia, M., Torres-Mejia, G., Colchero, M. A. \& Gonzalez de Cosio, T. Breastfeeding Mode and Risk of Breast Cancer: A Dose-Response Meta-Analysis. J Hum Lact 33, 422-434, https://doi.org/10.1177/0890334416683676 (2017).

23. Islami, F. et al. Breastfeeding and breast cancer risk by receptor status-a systematic review and meta-analysis. Ann Oncol 26, 2398-2407, https://doi.org/10.1093/annonc/mdv379 (2015).

24. Faupel-Badger, J. M. et al. Postpartum remodeling, lactation, and breast cancer risk: summary of a National Cancer Institutesponsored workshop. J Natl Cancer Inst 105, 166-174, https://doi.org/10.1093/jnci/djs505 (2013).

25. Scoccianti, C. et al. European Code against Cancer4th Edition: Breastfeeding and cancer. Cancer Epidemiol 39(Suppl 1), S101-106, https://doi.org/10.1016/j.canep.2014.12.007 (2015).

26. Martinez, M. E. et al. Reproductive factors, heterogeneity, and breast tumor subtypes in women of mexican descent. Cancer Epidemiol Biomarkers Prev 22, 1853-1861, https://doi.org/10.1158/1055-9965.EPI-13-0560 (2013).

\section{Acknowledgements}

The author wish to thank the substantial support provided by the research nurses and health workers as well as Tracy Lignini, Dacia Christin, Cecile Le Duc, Jordi de Battle, and Talita Duarte-Salles, Ana Cristina Ocampo for the logistic and data basis development and Karen Muller for English editing. The study is funded by the International Agency for Research on Cancer (IARC), the Union for International Cancer Control (UICC), the Pan American Health Organization (PAHO), the Ibero-American Programme for the Development of Science and Technology (CYTED), COLCIENCIAS (grant $\left.n^{\circ} 1115-569-348899\right)$, Universidad de Antioquia (grant CPT1229 and Estrategia de Sostenibilidad 2013-2014 to Group Infection and Cancer). For Dr. His, the work reported in this paper was undertaken during the tenure of a postdoctoral fellowship awarded by the International Agency for Research on Cancer, financed by La Ligue contre le cancer. The funders had no role in study design, data collection and analysis, decision to publish, or preparation of the manuscript. Ana Cecilia Rodriguez was part of the Proyecto Guanacaste when this work was carried out. 


\section{Author Contributions}

I.R., S.R., G.T., G.S., A.C.R., M.L.G., C.P. and P.P. designed the study. G.T., G.S., A.C.R., M.L.G., C.P., E.N., R.O., E.B., A.A., R.J. and members of the PRECAMA team (J.T., C.A.O., W.A., G.B., M.B., A.C., I.D., C.E., F.H., A.H., Y.R., B.C., P.G., D.G., V.L., F.G., J.S.) collected the data and sample materials. P.P. and M.O. designed the specific protocols for IHC and genetic analyses and conducted molecular analyses. CB and MC assembled the databases and analyzed the data. I.R., S.R., G.T., G.S., A.C.R., and M.L.G. interpreted the data. All authors participated in writing the manuscript. All authors read and approved the final manuscript.

\section{Additional Information}

Competing Interests: The authors declare no competing interests.

Publisher's note: Springer Nature remains neutral with regard to jurisdictional claims in published maps and institutional affiliations.

(c) (1) Open Access This article is licensed under a Creative Commons Attribution 4.0 International License, which permits use, sharing, adaptation, distribution and reproduction in any medium or format, as long as you give appropriate credit to the original author(s) and the source, provide a link to the Creative Commons license, and indicate if changes were made. The images or other third party material in this article are included in the article's Creative Commons license, unless indicated otherwise in a credit line to the material. If material is not included in the article's Creative Commons license and your intended use is not permitted by statutory regulation or exceeds the permitted use, you will need to obtain permission directly from the copyright holder. To view a copy of this license, visit http://creativecommons.org/licenses/by/4.0/.

(C) The Author(s) 2018 


\section{Consortia \\ On behalf of the PRECAMA team}

Jenny Tejeda ${ }^{3}$, Fancy Gaete ${ }^{12}$, Jose Soto ${ }^{13}$, Gonzalo Alberto Angel ${ }^{14}$, Carlos Andres Ossa ${ }^{20}$, William H. Arias ${ }^{15}$, Gabriel Bedoya ${ }^{15}$, Mauricio Borrero ${ }^{16}$, Alicia Cock-Rada ${ }^{17}$, Israel DíazYunez $^{18}$, Carolina Echeverri ${ }^{17}$, Fernando Herazo ${ }^{17}$, Angel Hernández ${ }^{19}$, Yorlany Rodas Cortes ${ }^{5}$, Bernal Cortes ${ }^{7}$, Paula Gonzalez ${ }^{7} \&$ Diego Guillen ${ }^{7}$

${ }^{12}$ Hospital Santiago Oriente Dr. Luis Tisné Brousse, Santiago, Chile. ${ }^{13}$ National Institute of Cancer, Santiago, Chile. ${ }^{14}$ Torre Médica Las Américas, Medellín, Colombia. ${ }^{15}$ GENMOL Group, Natural and Basic Sciences Faculty, University of Antioquia, Medellín, Colombia. ${ }^{16}$ Clínica Vida Fundacion, Medellín, Colombia. ${ }^{17}$ Instituto de Cancerología Las Américas, Medellín, Colombia. ${ }^{18}$ Imágenes Diagnósticas y Biotecnología Reproductiva, Cediul S.A., Barranquilla, Colombia. ${ }^{19}$ Clínica Bonnadona Prevenir, Barranquilla, Colombia. ${ }^{20}$ Torre Médica El Tesoro, Medellín, Colombia. 